\title{
Imbricaciones reticulares fraguadas a la sombra de un almendro
}

Patricio Estévanez y sus redes sociales

\section{Cristian Díaz Rodríguez}

\section{(2) OpenEdition}

\section{Journals}

Edición electrónica

URL: https://journals.openedition.org/cher/547

DOI: 10.4000/cher.547

ISSN: 2803-5992

\section{Editor}

Presses universitaires de Strasbourg

\section{Edición impresa}

Fecha de publicación: 10 junio 2021

Paginación: 153-174

ISBN: 9791034400928

ISSN: 1968-035X

\section{Referencia electrónica}

Cristian Díaz Rodríguez, «lmbricaciones reticulares fraguadas a la sombra de un almendro»,

reCHERches [En línea], 26 | 2021, Publicado el 11 octubre 2021, consultado el 17 noviembre 2021. URL: http://journals.openedition.org/cher/547 ; DOI: https://doi.org/10.4000/cher.547 


\section{Imbricaciones reticulares fraguadas a la sombra de un almendro Patricio Estévanez y sus redes sociales}

CRIStian Díaz Rodriguez*

[...] el que su sombra en la niñez me daba vivirá mientras haya trovadores en la tierra sin par de mis amores.

Nicolás Estévanez (a Patricio), Confidencial

Cuando, en 1917, Patricio Estévanez y Murphy se ve obligado a abandonar la dirección del Diario de Tenerife, este «maestro de periodistas» (Guimerá Peraza 1974: 89) redacta un artículo, «Uno que se rinde», en el que reflexiona sobre su «[m]edio siglo de intervención constante, aunque modesta y oscura, en la vida pública [...]» (Estévanez Murphy 01/01/1917: 1). Sin embargo, la relación de Patricio Estévanez con la élite intelectual, económica y política del Tenerife decimonónico no sabría, en modo alguno, reducirse a su faceta de periodista, pues, sin duda, la propia existencia de este prohombre, en ocasiones injustamente eclipsada por «la sombra del viejo almendro ${ }^{1}$ del viejo poeta muerto e inmortal ${ }^{2}$ » (Gil-Roldán 01/01/1917:1), es indisociable de la sociedad santacrucera finisecular ${ }^{3}$.

* Cristian Díaz Rodríguez, Université de Strasbourg, UR 4376-CHER. ORCID: 00000002-7519-7376, <cdiazrodriguez@unistra.fr>.

1 El almendro que daba sombra a la habitación de Nicolás Estévanez durante su niñez, y que en su poesía representa la nostalgia de alguien alejado de su terruño amado, pasa a convertirse, en el marco imperante del Romanticismo, y alentado por la pujanza de los nacionalismos en ciernes, en un elemento alegórico que hace referencia a Canarias, entendida como «patria chica».

2 Referencia al poeta, militar y político Nicolás Estévanez Murphy (1838-1914), hermano mayor de Patricio.

3 Las fechas de nacimiento y muerte de Patricio Estévanez (1850-1926) nos conducen a concebir el siglo xIx en su sentido más amplio, conforme al período histórico que Eric J. Hobsbawn denominara el largo siglo XIX. 
Perteneciente a una saga de ilustres personajes, miembro destacado de varias asociaciones radicadas en Tenerife, actor proactivo en la política santacrucera e infatigable y reconocido periodista, a lo largo de toda su vida, Patricio Estévanez se encargó de fraguar y cultivar una densa red de contactos, que se extendería desde su esfera íntima, familiar y privada, hasta aquella otra, más pública y abstracta, derivada del ejercicio de su profesión o de sus afinidades políticas. En este marco, propicio para que, según Maurice Agulhon (2016), se desarrolle y evolucione la sociabilidad, es donde Patricio Estévanez forjará su identidad social y, al mismo tiempo, se erigirá en común denominador de diversas redes sociales, entendidas estas como:

un conjunto de conexiones entre actores relacionados de un modo $u$ otro a través de interacciones efectivas que se producen en un momento dado [...] [lo que permite] observar, de la manera más completa posible, el conjunto de interacciones entre individuos para detectar las formas de articulación que estas revelan, desde los grupos o "cliques" de personas más vinculadas entre sí hasta las relaciones más ocasionales o alejadas de esos entornos densos. (Imízcoz y Arroyo 2011: 100)

A través del repaso biográfico de Patricio Estévanez y del estudio epistolográfico de una parte de la correspondencia enviada a este y conservada en el Fondo Estévanez ${ }^{4}$, así como de varios artículos publicados en la época, nos proponemos restablecer la configuración de las diferentes redes (familiares, amicales, profesionales, informacionales...) en las que se declina la sociabilidad de este ilustre personaje. Para ello, prestaremos especial interés a la identificación de los actores o nodos que las integran, lo que permitirá evaluar el grado de imbricación, cuando no de superposición, de las diferentes redes sociales de Patricio Estévanez. Se comprobará, además, que estas redes egocentradas vienen a identificarse, al mismo tiempo, con el entramado en el que se estructuran y organizan las élites del Santa Cruz de Tenerife del último tercio del siglo xix y de principios del $\mathrm{xx}$.

\section{El despertar social (1850-1872)}

Patricio Estévanez Murphy, el menor de los seis hijos que tuvieron en común el teniente coronel de infantería Francisco de Paula Estévanez y García Caballero e Isabel Murphy y Meade (Sánchez Morales 2006: 10), nació el 1 de julio de 1850 en Santa Cruz de Tenerife, en los albores de un período de

4 El legado documental Borges-Estévanez, atesorado en los Archivos del CEDOCAM -Centro de Documentación de Canarias y América- en San Cristóbal de La Laguna (Tenerife), está constituido por una ingente cantidad de documentos manuscritos de diversa índole: desde correspondencia personal o profesional hasta trabajos científicos o literarios, folletos o fotografías, de los que, principalmente, se habían hecho acopio a lo largo de su vida los hermanos Nicolás y Patricio Estévanez. Este fondo se halla actualmente en proceso de clasificación y catalogación, lo que justifica, en cierta medida, la imposibilidad de escudriñarlo de manera exhaustiva. 
inestabilidad política, a escala nacional e insular, que se extendería a lo largo de toda la segunda mitad del siglo xix. En 1862, sin todavía cumplir los doce años, quedó huérfano, situación que lo obligaría a abandonar la ciudad que lo vio nacer, asolada a la sazón por la fiebre amarilla, para encontrar refugio en la casa familiar de Santa María de Gracia, en La Laguna, donde quedaría al cuidado de su abuela Isabel y de una tía materna, y bajo la tutela legal del médico marsellés Barthélémy Saurin Liautaud, fallecido pocos meses más tarde a consecuencia del vómito negro (Sánchez Morales 2006: 14). Apenas unos años después, entre 1886 y 1887, la fatalidad quiso despojar al joven Patricio de los pocos familiares que le quedaban en la Isla. En cuanto a su hermano Nicolás, este tuvo que dejar Canarias para trasladarse a Toledo para proseguir sus estudios militares, que pronto lo llevarían a comprometerse políticamente con la causa republicana ${ }^{5}$.

Patricio decide, entonces, quedarse en Tenerife para acabar sus estudios en el Instituto Provincial de La Laguna ${ }^{6}$. Será en el seno de esta celebérrima institución de enseñanza donde este, tal vez como una forma de suplir el vacío que le produce su orfandad, traba una serie de amistades entre sus profesores y, sobre todo, sus compañeros de clase, la mayoría nacidos en torno al año 1850, que, desde entonces, habrán de acompañarlo a lo largo de su vida. Así lo narra el propio Patricio en una carta enviada desde París (7/5/1879) a su amigo de la infancia Mateo Alonso del Castillo, para su publicación en la Unión Lagunera ${ }^{7}$ :

Abrumado bajo la tremenda pesadumbre de desgracias sin ejemplo, niño aún, huérfano y solo en el mundo, débil y enfermo, esperando y hasta deseando la muerte, llegué a la Laguna, y aquel clima sin igual, las muchas y sinceras amistades que allí contraje, la distracción que me proporcionaban mis estudios, el cariño, inmerecido quizá, que me prodigaron todas las personas que trataba y particularmente algunos de mis profesores, como D. Sebastián Álvarez, D. Silvestre Machado y el inolvidable D. José Pinto, el aire puro que respiraba en su deliciosa vega, me devolvieron la salud y si no olvidé mis desventuras, amé de nuevo la vida. (Estévanez 21/05/1879: 2)

Paralelamente a sus estudios en el Instituto, también recibe clases de pintura en la Academia Provincial de Bellas Artes (Sánchez Morales 2006: 14-15), de la mano de los pintores Gumersindo Robayna y Lazo, Nicolás Alfaro y Brieva y Francisco Aguilar y Fuentes. Es probablemente en este marco donde traba amistad con el pintor palmero Manuel González Méndez, pues este reza como matriculado entre los años 1868 y 1869 (Rodríguez Escudero 2009). Sánchez

5 El lector interesado en los detalles biográficos de Nicolás Estévanez puede consultar la obra redactada por Reyes González (2016).

6 Previamente había cursado sus primeras letras en el colegio del Sr. Celorrio (Sánchez Morales 2006: 11) y, bajo la tutela del presbítero Antonio Hernández, en el Seminario Conciliar (Guimerá Peraza 1974: 90).

7 En la reproducción de los fragmentos de las diferentes misivas, así como de los periódicos, se ha optado por mantener la ortografía utilizada, a excepción del uso de las tildes, que se ha actualizado conforme a las reglas vigentes, y de las abreviaciones taquigráficas, que se han desarrollado. 
Morales, al valorar esta primera etapa de la vida de Patricio Estévanez, afirma que "fue clave por la red de amistades que tejió en su Tenerife natal» (2006: 17), entre las que destacan personajes tan relevantes para la sociedad tinerfeña de finales de siglo, como: "Juan Ascanio y Nieves, Leandro Fajardo, Agustín Estrada, Blas Cabrera, José Tabares Bartlett, Antonio, Tomás y Elías Zerolo Herrera, Bernardo Benítez de Lugo, José Manuel Pulido o Francisco María Pinto» (Sánchez Morales 2006: 17-18).

Aunque difícilmente aislable de esta red privada de amistades, Patricio pronto comienza a urdir los primeros hilos de lo que, más tarde, se convertirá en un denso tejido social, reflejo de su vida pública. De hecho, la primera mención explícita al menor de los Estévanez en la prensa tinerfeña se remonta al 30 de octubre de 1870, cuando apenas contaba con 20 años, con motivo de la primera sesión pública de la Sociedad Instructiva de La Laguna, recientemente fundada al amparo de las libertades que trajo consigo la revolución Gloriosa (1868):

El acto tuvo lugar en el Salón de Grados del instituto de $2^{a}$ enseñanza, en medio de una grande y escojida $[s i c]$ concurrencia, de la que el bello sexo formaba una no pequeña parte. [...] El Sr. Estévanez (D. Patricio) llamó con la elocuente voz del patriotismo, a que diesen su apoyo a aquella naciente sociedad, los que por su posición y saber pueden prestarle grandes servicios. (La Federación 30/10/1870: 2).

En esa sesión, según podemos leer en la misma publicación, además del presidente de la Sociedad Instructiva, también tomaron la palabra: Juan Ascanio y Nieves, Leandro Fajardo, Antonio Hernández Rojas, Isidoro García, Emilio Monasterio y Mandillo, Francisco Fernández Bethencourt, Miguel Alfonso y González, José Tabares Bartlett, Rafael Calzadilla y José Manuel Pulido estos dos últimos, junto con [¿Pablo?] Ferreira, actuaban, al mismo tiempo, como representantes del Gabinete Instructivo de Santa Cruz. Resulta bastante curioso comprobar que, pese a la afinidad existente entre los ideales y objetivos seguidos por la Sociedad Instructiva y el Gabinete Instructivo, y a la estrecha amistad de nuestro biografiado con buena parte de los miembros de este último - especialmente con Elías Zerolo, quien, se supone, «debió ser el autor de la feliz iniciativa» (Martínez Viera 1967: 117)-, Patricio Estévanez no figure entre los fundadores de la institución santacrucera ${ }^{8}$.

A estos contactos, derivados de sus actividades culturales y filantrópicas, se vienen a sumar otros, resultantes de la incipiente práctica periodística de

8 En el acta fundacional aparecen rubricados los nombres de cuarenta socios, entre los que podemos señalar, por su relevancia con los objetivos perseguidos por este artículo, los de: Antonio Delgado Yumar, Abelardo Bonnet, Alfonso Dugour, Elías Zerolo, Ireneo González, Juan de la Puerta Canseco, Juan M. Ballester, José Tabares Barlett, José Manuel Pulido, Manuel Quintero, Rafael Calzadilla o Valentín Sanz y Carta (para conocer la lista completa, véase Cola Benítez 2001: 33-34). Esta nómina de próceres pronto se verá engrosada por muchos otros socios, entre ellos, algunos que ya se encontraban presentes durante la reunión en la que se gesta el Gabinete Instructivo (Cola Benítez 2001: 29): el marqués de La Florida, Villalba Hervás, Darío Cullen Sánchez, Gabriel Izquierdo y Azcárate, Ramón Gil-Roldán y Río o José D. Dugour. 
Patricio Estévanez. Ávido lector de la prensa, sobre todo de aquella de corte democrático y revolucionario, desde muy joven publicaría artículos breves y crónicas, sin rubricar, en el Progreso de Canarias, dirigido por el marqués de la Florida, en La Federación, con Miguel Villalba Hervás al frente y en el diario Las Noticias, fundado por Rafael Calzadilla y dirigido por Alfonso Dugour Ruz, dos de los más estrechos amigos del menor de los Estévanez (Sánchez Morales 2006: 17-18).

Como se puede apreciar, muchos de los eruditos reunidos en estas embrionarias sociedades literarias provienen de importantes familias de la burguesía comercial tinerfeña. Ellos conformarán el germen de lo que, a lo largo del último tercio del siglo XIX y primero del $\mathrm{xx}$, se consolidará como las élites culturales, económicas y políticas de Santa Cruz de Tenerife. Además de hallar en estos espacios de cultura un lugar privilegiado para el debate, esta pléyade encontrará en la práctica periodística, motivada por la profusa cantidad de periódicos surgidos durante toda la mitad de la centuria (Yanes Mesa 2003), una tribuna para la exposición de ideas de toda índole.

\section{Errancia lejos del almendro}

En enero de 1872, Patricio Estévanez toma la difícil decisión de abandonar la dulce, fresca e inolvidable sombra del almendro de Gracia, para aventurarse en tierras peninsulares, junto a su hermano mayor. El advenimiento de la primera república (1873) supondrá una etapa política muy activa para Nicolás en la ciudad del madroño: diputado a Cortes por Santa Cruz de Tenerife, gobernador civil de la capital durante el gobierno de Estanislao Figueras y ministro de la Guerra durante el gobierno de Pi y Margall (Reyes González 2016, vol. 1: 219-270). Suponemos que Patricio, fiel acólito de su hermano, se codeará con la flor y nata de la política republicana de la época: Salmerón, Pi y Margall, Ruiz Zorrilla... De hecho, tras su llegada a Madrid, comienza a colaborar en el diario de ideología republicana radical $\mathrm{El} \mathrm{Combate} \mathrm{Co}^{9}$, dirigido por Ignacio Sastre, Enrique Rodríguez Solís y Francisco Rispá y Perpiñá. Según Sánchez Morales (2006: 19), entre este último y Patricio Estévanez se fraguará una íntima amistad. Sin embargo, poco se conoce de la etapa madrileña del menor de los Estévanez. Lo que sí sabemos es que Patricio seguirá manteniendo una estrecha relación con sus amigos de la infancia ${ }^{10}$, como demuestra, a título de ejemplo, una carta que le escribe desde París Manuel González Méndez, quien, no en vano, lo considera «en el primer rango de [sus] mejores amigos»:

9 En la etapa en la que participa Patricio Estévanez, sin embargo, el diario ya había suavizado notablemente la radicalidad del discurso que lo había caracterizado durante la etapa en la que José Paúl y Angulo ostentaba su dirección (Pérez Roldán 1999).

10 Muchos de sus antiguos compañeros del Instituto Provincial de La Laguna cursan estudios superiores durante esta época en la Universidad Central de Madrid. 
No por los periódicos (pues yo no leo jamás) pero sí por nuestros amigos Flors [sic] supe en su tiempo los elevados citios [sic] que su hermano de V. había ocupado en la administración de ese pobre país y mi satisfacción fue tan grande como grande fue también mi sentimiento al saber su caída [...] (CEDOCAM_ FE_179)

Con la Restauración borbónica (1874), los dos hermanos se ven obligados a un exilio no exento de adversidades. Antes de alcanzar la bohemia parisina -en aquella época, destino final de muchos españoles- y de una breve estancia en Inglaterra, los Estévanez conocieron los sinsabores de un influenciable Portugal (1874-1875). Si bien, por una parte, esta tierra proporcionó a Patricio la oportunidad de tomar un primer contacto con el mundo editorial al publicar Miscelánea ilustrada y fundar y dirigir la revista infantil La floresta de la Juventud (Sánchez Morales 2006: 21), por otra, el Gobierno luso cedió ante las presiones de su homólogo español para que se expulsara del país al antiguo ministro republicano de la Guerra ${ }^{11}$.

Sabemos, que, durante este periodo, ambos hermanos siguen manteniendo una estrecha relación con muchos de sus amigos de la infancia. En cuanto a la malla de contactos de los Estévanez en el país vecino, creemos que esta debió ser bastante considerable, pues se extendía por las ciudades de Lisboa, Cascaes y Oporto. Desafortunadamente, las fuentes consultadas no nos permiten restablecer los nodos que configuraban dichas redes de contactos. De hecho, en la correspondencia consultada tan solo hemos encontrado a un remitente, Bernardino García Parra, quien afirma haber compartido con los hermanos Estévanez cinco años de emigración: «[...] dígame de su familia y de aquellos niños de París que supongo hombres en Madrid. [Q]uiero también saber de mi querido Patricio con quien vivía en Lisboa cuando V. estaba en Oporto [...]». (CEDOCAM_FE_3412).

\section{El exilio parisino (1876-1880)}

Una vez instalados en París, ambos hermanos comenzaron a trabajar para la editorial Garnier Frères. Para ella, Patricio publicó El buen novelista, varias traducciones ${ }^{12}$, una adaptación al castellano de una guía de París y una guía de

11 Patricio, al haber permitido, supuestamente, la huida de su hermano, fue encarcelado durante un breve periodo de tiempo (Martínez Viera 1967: 196).

12 Contrariamente a lo que sostiene Guimerá Peraza (1974: 93), en su tesis doctoral, Fischer Hubert (1994) identifica como única traducción de Patricio Estévanez El microscopio del doctor Bollenger o el Hombre microscopio (1882). La traducción de Curiosidades del mundo de los insectos: un té científico y Las hormigas (1880), por su parte, correspondería a un tal Dr. Arana (Fischer Hubert 1994: 337), nombre que, se asemeja a uno de los pseudónimos empleados por Nicolás Estévanez. Sin embargo, hemos podido comprobar, en reediciones de la obra, que ciertamente el traductor de la obra es Patricio Estévanez. Además, Fischer Hubert habla de una posible traducción de una obra de Alexandre Dumas, que el periodista habría enviado a Canarias, y que, por tanto, se habría realizado fuera de los encargos realizados por la editorial Garnier. Según la información reflejada en el índice del tomo I de la Revista 
la Exposición del $78^{13}$ (Guimerá Peraza 1974: 92). En muy poco tiempo, tanto Nicolás como Patricio consiguieron hacerse un hueco en la sociedad parisina conformada por emigrados españoles, entre los que se hallaban personalidades de la talla de Pi y Margall, Castelar, Blas Pierrad, Ruiz Zorrilla, Alberto Araus o Prim. Aunque no de forma continua, también coincidieron en la Ciudad de la Luz con varios paisanos de la patria chica, como el pintor Manuel González Méndez, el periodista Juan Maffiotte o el médico Juan Real. Sin embargo, las relaciones con las gentes del país galo parecen ser casi anecdóticas durante estos años. El propio Nicolás Estévanez, en sus Rastros de la vida, revela que, aunque luego cambia de opinión, «al principio de su estancia en París trató muy poco con los franceses: "los tenía cierta ojeriza, creyéndolos a todos monárquicos reaccionarios”» (Estévanez 1903: 509 apud Fischer 1994: 405). Hemos de suponer que, Patricio Estévanez, por su parte, repetiría este mismo patrón, lo que explicaría que, en la correspondencia que recibe desde París tras su vuelta a Tenerife no se encuentre ningún remitente de nacionalidad francesa.

Durante los cuatro años que Patricio pasó en París, en cambio, este será un habitual de las tertulias improvisadas en el café de Madrid, sito en el bulevar de Montmartre. En este emblemático espacio de sociabilidad, el menor de los Estévanez confraternizará con exiliados españoles de todo signo político -desde anarquistas a carlistas-, con muchos de los cuales logrará fraguar una auténtica amistad, como ilustra la proyección de un viaje a pie entre París e Italia, que sabemos frustrado:

Hallábamos reunidos como de costumbre en el Café de Madrid, situado en el bulevard Montmartre y punto de reunión de muchos españoles, varios amigos, emigrados casi todos, aunque de distintas proce[dencia]. En torno de una mesa [...] estábamos el teniente coronel Delgado, Emilio Zorrilla, el doctor Alonzo y el que estas líneas escribe. Si alguno de los lectores conociere a estos cuatro personajes no necesitaría que yo le dijese que en política no pensábamos de la misma manera, cosa rara entre españoles, pero esto no impide que nos lleváramos bien y que ni siquiera hablásemos de la cosa pública, como no fuera para desesperar al amigo Alonzo, único monárquico y carlista por añadidura. (CEDOCAM_FE_1780).

En este ambiente, alejado aún de lo que será la bohemia parisina de finales del xIx y principios del xx (cfr. López Lapuya s.f.), los Estévanez pasan a ocupar una posición privilegiada dentro del engranaje social constituido por los españoles en la diáspora. Si Nicolás Estévanez «es la primera personalidad en la colonia española de París, no por haber sido ministro de la guerra [...]

de Canarias, se trataría de la traducción de la leyenda Los Buondelmonte y los Bardi. Además, habría que añadir a la lista de obras de Patricio Estévanez la adaptación de la novela Los condes de Eberstein.

13 Según Sánchez Morales, estos dos últimos trabajos no fueron realizados para la editorial Garnier Frères sino por petición de un editor chileno: «Todo resultó ser una estafa $y$, una vez entregados los trabajos, el editor desapareció sin pagarle lo acordado.» (2006: 22). 
sino por ser don Nicolás» (Bonafoux y Quintero 1907), Patricio ostentará en esa época, según declaraciones de su propio hermano, el título de «cónsul general isleño» (Guimerá Peraza 1974: 92). No sabemos si tal consideración lo llevaría a emular ciertas prácticas sociales y a frecuentar determinados espacios de sociabilidad reservados ya no a la élite intelectual, local o emigrada, de sobra confirmada $^{14}$, sino aquella más bien de naturaleza política y social. Aunque podemos afirmar que tampoco le eran totalmente ajenos. De hecho, en el Fondo Estévanez, se conserva una invitación dirigida a Patricio (CEDOCAM_FE_670), enviada en nombre del ministro de Agricultura y Comercio y de su esposa Mme Teisserene de Bort, para pasar una velada en las instalaciones ministeriales. Lo que sí podemos aseverar, con total seguridad, es que era buen conocedor del circuito cultural que la capital francesa, esa "gran ciudad de los espectáculos y los placeres» (Estévanez 08/05/1879: 171), ofrecía a cualquier bolsillo: desde óperas y conciertos reservados a un selecto grupo social hasta reuniones y tertulias abiertas al público, sin olvidar las carreras de caballos o los numerosos museos:

[...] hace pocos días tuve el gusto de visitar el curiosos museo que en su casa particular ha formado M. Vernaud [sic] con los objetos que trajo de Canarias al regresar de su expedición científica a nuestras islas. [...] A los sabios les ha llamado mucho la atención; la antropología parece que sacará gran partido de todos ellos, pero, por mi parte, sólo puedo decir que lo visité con muchísimo gusto, pues, siéndome tan conocidos y familiares todos aquellos objetos, me creí por un momento trasportado a mis peñas inolvidables. (Estévanez 08/05/1879: 173)

A pesar de su exilio parisino, Patricio Estévanez siempre se mantuvo al tanto de la actualidad política, social y cultural de Canarias, especialmente de la tinerfeña, pues el frecuente intercambio epistolar que mantenía con sus contactos isleños le ofrecía un testimonio directo de cuanto acontecía en las Islas. Así leemos, por ejemplo, en una carta enviada por Antonio Llombet poco después de la instalación de los hermanos en París: «Esta noche hay gran sesión en el Gabinete; se lee la biografía de Florida, que ha escrito para este acto Villalba ${ }^{15}$ » (CEDOCAM_FE_168). De este modo, su red de contactos y amistades también se convirtió, por así decirlo, en una red informacional que lo mantenía en contacto con la realidad del Tenerife decimonónico. Además, como complemento informativo, sus amigos y conocidos le hacían llegar paquetes con revistas y periódicos editados en el Archipiélago.

En el sentido inverso, Patricio también se encargaba de alimentar la red saciando entre sus compatriotas las ansias de información proveniente de la Ciudad de la Luz: «Estamos ávidos de noticias ¿qué hay? ¿qué hay? ¿qué hay?»

14 «Hace pocas noches asistí al tercer banquete mensual de la Sociedad La alianza latina, y difícilmente podré olvidar la impresión que me causó aquella reunión, compuesta en gran parte de eminencias de las letras, las ciencias y la política, y en la que no dejó de reinar ni un solo instante la cordialidad más franca y el entusiasmo más sincero por la idea que la asociación representa.» (Estévanez 08/05/1879: 172)

15 Esta ponencia habría motivado la clausura del Gabinete Instructivo por parte de las autoridades locales. (Cola Benítez 1998) 
(CEDOCAM_FE_168). De hecho, en aras de satisfacer, por un lado, esta sed manifestada en diversas ocasiones por sus amigos, y, por otro, suponemos, de desarrollar su faceta periodística para completar su labor editorial, Patricio actúa de corresponsal para varios periódicos tinerfeños (Las Noticias, El Memorándum, Unión lagunera), cubanos, mejicanos y peninsulares (El Globo). Especialmente importante será su "Correspondencia de París», publicada en la Revista de Canarias - que dirigía su entrañable amigo Elías Zerolo-, a través de la cual mantendrá informado a los lectores tinerfeños de los acontecimientos más relevantes producidos en la capital francesa ${ }^{16}$. La correspondencia mantenida entre Patricio y sus amigos durante su exilio parisino deja constancia de que no solo estaban interesados en lo que sucedía en el país galo, sino que también era de su interés todo aquello que se dijese en Francia sobre la política y la sociedad española:

Nos dicen que el periódico "Le Bien public", está insertando unas correspondencias de Madrid; ¿no sería fácil, que V. las cortara y que las mandara por conducto de Don Benjamín Delgado, que las remitiría a Juanito Ballester con sobre para mí [Antonio Llombet]? (CEDOCAM_FE_168)

Se infiere de estas palabras la complejidad de la red de personas que funcionaban como receptores intermediarios de la correspondencia ${ }^{17}$. Dicha trama surge como reacción frente al peligro de que las diferentes misivas $y$, por consiguiente, la información, se perdiera o fuera interceptada $\mathrm{y}$, a tenor de su contenido, se pudieran tomar represalias contra su destinatario, como deja entrever Antonio Llombet a Patricio al preguntarle: «¿Por qué no escribe V. por esta vía [de Inglaterra] que es más segura?» (CEDOCAM_FE_168). Esto explicaría que la misma información se enviara por diferentes vías y que se diversificaran los nodos intermedios, por conducto de quienes las cartas alcanzaban a su destinatario final. En este sentido, hemos de destacar la labor de Benjamín Delgado, uno de los socios de la Commission Delgado et Cie. ${ }^{18}$, a la hora de recibir los envíos destinados a los Estévanez en París, de quien tenemos cuenta en una misiva que este envía el 21 de noviembre de 1881 a Nicolás Estévanez para disculparse por el retraso sufrido en la entrega de unas cartas, debido a un extravío:

Hoy necesitando papel para encender mi chimenea, desdoblo este $\mathrm{n}^{\circ}[\mathrm{del}$ Memorándum] y me encuentro con la adjunta correspondencia dirijida [sic] a V.

16 La colaboración con la Revista de Canarias, en realidad, se limita al envío de cuatro crónicas publicadas entre 1878 y 1879. En el Fondo Estévanez se conserva una carta redactada por Patricio Estévanez (CEDOCAM_FE_4144), que, suponemos, debería haberse publicado en la sección de «Correspondencia de París» a principios de 1880. Sin embargo, esta nunca verá la luz, pues, como veremos ulteriormente, el regreso definitivo de Patricio Estévanez a Canarias se produce en febrero de ese mismo año.

17 Pese al interés que suscita este aspecto, en este trabajo tenemos que renunciar a su desarrollo dadas las limitaciones de espacio impuestas.

18 Especialistas en importación de cochinilla, sito en el número 26 de la calle d'Eughien, París. 
que me apresuro a remitirle. Si pesa pues sobre mí alguna sospecha de interceptar correspondencia, levántemela pues. (CEDOCAM_FE_940)

A pesar de su doble actividad profesional-el mundo editorial y el periodismo-, los ingresos de Patricio Estévanez no eran para nada boyantes. De hecho, los años pasados en París vendrían más bien a esquilmar su salud y su bolsillo, lo que despertaría en él las ganas de regresar a las Islas, tal y como comenta su hermano Nicolás a su amigo Gil-Roldán en una carta fechada el 10 de enero de 1880: «No vayas a creer que estoy chiflado: el que lo está es Patricio que se quiere ir a Canarias. Sin embargo, puede que este viaje convenga a su salud» (Guimerá Peraza 1975: 88). De hecho, a lo largo de su estancia francesa, son constantes las ofertas pecuniarias que, en sus cartas, le hacen sus amigos más íntimos con la intención de mitigar las penurias por las que está pasando y de alentar su regreso a la Isla: «Con toda franqueza, dígame si quiere que le envíe algunos francos, en calidad de como V. quiera. Conmigo no hay reticencias sino clarito.» (CEDOCAM_FE_168).

El regreso a Canarias de Patricio Estévanez no supondría en ningún caso una ruptura total con la red de contactos y amistades parisinas. Si nos limitamos a los compatriotas isleños, en la capital francesa quedarán, por un lado, eslabones esenciales de su cadena relacional, como Manuel González Méndez, Juan Real y, sobre todo, su hermano Nicolás, su cuñada Concha y sus sobrinos. Además, esta red se verá fortalecida mediante la incorporación, en distintas épocas, de nodos fundamentales para Patricio, como los que constituyen el periodista Juan Maffiotte; el militar, político y jefe de la Casa Real de Alfonso XII, Imeldo Serís; su inestimable Elías Zerolo, periodista y republicano convencido, director de la Revista de Canarias; y el ingeniero de minas e hijo de este último, Miguel Zerolo.

\section{De vuelta a casa (1880-1926)}

El 3 de febrero de 1880, Elías Zerolo, sin disimular su afecto y satisfacción, se hace eco de la llegada de Patricio Estévanez a Tenerife en su «Conversación quincenal» en la Revista de Canarias:

Tenemos entre nosotros a nuestro queridísimo amigo y colaborador D. Patricio Estévanez. [...] Una cruel enfermedad, de la que está convaleciendo, obliga a nuestro querido amigo a pasar algunos meses en estas sus queridas peñas. Lamento la causa, pero no puedo ocultar la satisfacción con que le he visto por aquí, no solo por el gusto de verle, sino también porque siendo Estévanez el canario más canario que he conocido, ha de forzosamente producirle reparador bienestar el aspirar los aires de la patria, de suyo saludables. (Zerolo 03/02/1880: 47)

Lo que no llega a adivinar el insigne periodista es que el regreso de su amigo, lejos de ser temporal, sería definitivo: este ya no volvería a abandonar su retiro familiar ${ }^{19}$, por aquel entonces, integrado en el barrio de Geneto, en La Laguna.

19 En diferentes épocas, la casona de Gracia daría albergue a insignes personajes, como Sabin Berthelot, Adolphe Coquet, Leopoldo O’Donnell o Vicente Blasco Ibáñez. 
Al soco de los muros de la plaza en la que se erige la ermita de Santa María de Gracia, pronto se vuelven a reunir las más ilustres personalidades de la élite cultural tinerfeña. Emulando épocas pretéritas en las que encendidos debates de la sociedad "volcanista» ${ }^{20}$ abandonaban la calle de La Noria, en Santa Cruz, para proseguir en un ambiente más distendido, bajo el celebérrimo almendro de Nicolás Estévanez (Rodríguez 2001 [1940]: 198-199), el templo se ve despojado eventualmente de su funcionalidad religiosa para dar cabida, con el beneplácito de su mayordomo, Patricio Estévanez, a temas de índole civil ${ }^{21}$ : política, arte, ciencias, agricultura..., debatidos en el seno de la tertulia homónima, integrada por «[m] úsicos, pintores, poetas, publicistas, sacerdotes... Teobaldo Power, Valentín Sanz, Almeda, Alfonso Dugour, Elías y Antonio Zerolo, Francisco María Pinto, Moure, Tabares, y tantos otros que constituían lo más selecto de la intelectualidad insular [...]» (Rodríguez 2001 [1940]: 199). Nombres que, en su mayoría, ya aparecían ligados al de Estévanez desde la infancia. De hecho, nada más llegar a la Isla, retoma sus viejos contactos y, paralelamente, establece nuevas relaciones, derivadas, principalmente de su actividad cultural y periodística, lo que conllevará un aumento considerable de la extensión de sus redes sociales.

\section{Asociacionismo, compromiso social y patriotismo}

El regreso de Patricio Estévanez a Tenerife supondrá igualmente su inmediata vuelta a la esfera pública. Apenas instalado, se involucra afanosamente en todos los actos organizados por el Gabinete Instructivo de Santa Cruz, del que pasará a ser socio tras su reapertura en $1880^{22}$. Se mostrará especialmente activo en la organización de eventos de carácter conmemorativo, como los actos en torno a la Gesta del 25 de julio contra Nelson, en 1880 y 1882, o las veladas literarias celebradas en homenaje a Cervantes (1881) y a Calderón (1881). Su participación, sin embargo, no se limitaría a las gestiones meramente organizativas, sino que también desempeñaría un papel fundamental en el programa de actos. En la velada calderoniana de 1881, por ejemplo, Patricio interpretó algunas escenas de La vida es sueño, junto a Luisa Pebrer, y puso voz a una composición de Francisco María Pinto (Martínez Viera 1967: 122); y, justamente en la velada necrológica que el Gabinete organizó a este último en 1887, en la que también participaron personajes como Villalba Hervás, Antonio Zerolo, Azcárate, Puerta Canseco, Rafael Calzadilla, Luis Maffiotte o Gil-Roldán, Patricio leyó una semblanza de Pinto.

20 Además de a Nicolás Estévanez, Leoncio Rodríguez (2001 [1940]: 198) identifica como miembros de la «peña», e intimísimos amigos del primero, a Agustín Guimerá, Fernando León, Ramón Gil-Roldán y Gaspar Fernández.

21 No la ermita, pero sí la casa de Gracia se convertiría ulteriormente en un templo del saber, al albergar en un salón de la primera planta «la escuela particular de Gracia, una escuela con más de cincuenta alumnos de ambos sexos», tras la realización de un concurso abierto en el Diario de Tenerife (Roger 30/03/1909: 1).

22 Pese a que la Sociedad Instructiva de La Laguna sigue en activo hasta 1882, no hemos podido hallar testimonios que demuestren la reanudación del periodista con esta tras su vuelta, más allá de aquellas fuentes que lo sitúan al frente de esta institución. 
Si bien el Gabinete Instructivo aspiraba principalmente a ser un órgano de divulgación cultural, como testimonian sus veladas culturales e históricas, sus conferencias dominicales para mujeres o el apoyo e impulso dado a proyectos como la creación de la Biblioteca Municipal (1888), lo cierto es que las exposiciones de arte o las sesiones literarias celebradas a puerta abierta en sus salones, con frecuencia, daban paso a acaloradas discusiones y nutridos debates de naturaleza política. El intercambio de ideas y opiniones emitidas por los socios encontraba entre las paredes del Gabinete Instructivo la libertad y la tolerancia necesarias para ser expresadas. Estas características han sido esgrimidas, en ocasiones, como argumento para ver en este grupúsculo asociativo un instrumento de las logias masónicas, tan presentes en el Santa Cruz de finales del siglo xIx. Sin embargo, como nos recuerda Cola Benítez (1998), los ideales políticos de los socios reunidos en el Gabinete Instructivo cubrían todo el espectro político: monárquicos y republicanos, conservadores y progresistas, unionistas y federalistas, carlistas y anarquistas... y, cómo no, también masones. De hecho, el propio Patricio Estévanez, declarado republicano federalista, pertenecía, al igual que muchos otros socios del Gabinete, a logias masónicas ${ }^{23}$, en concreto a Hijos del Teide $n^{\circ} 94$ y Tinerfe $n^{\circ} 114$, y llegaría a alcanzar el grado $18^{\circ}$ (cfr. Aguiar Bobet en este monográfico).

Este alejamiento de los fines meramente culturales a los que, en un principio estaba destinado el Gabinete Instructivo ${ }^{24}$, alimentará el recelo de las autoridades locales, con las que, sin embargo, colaboran estrechamente en labores de consulta y asesoramiento. Ya, en una ocasión, se había procedido a la clausura del Gabinete, tras la celebración de una velada en la que se leyó una biografía del marqués de la Florida redactada por Miguel Villalba Hervás, lo que había llevado a algunos de sus socios a crear sociedades alternativas que permitieran seguir llevando a cabo las labores del Gabinete, como el Establecimiento de Segunda Enseñanza de Santa Cruz, el Gabinete Científico de Santa Cruz de Tenerife o la Revista de Canarias (Cola Benítez 1998). Pero, la segunda y definitiva se produciría bajo la presidencia de Patricio Estévanez, en 1901, ante la imposibilidad de poder hacer frente a una multa impuesta a la tesorería del Gabinete tras una inspección de los libros de cuentas. Nuevamente,

23 La solicitud de afiliación de Patricio Estévanez a la logia Tinerfe $\mathrm{n}^{\circ} 114$ se llevará a cabo en 1880 (De Paz y Alfonso Da Costa 2008: 202), nada más regresar a Tenerife, coincidiendo con su fecha de adhesión al Gabinete Instructivo. Sin embargo, no se puede descartar que su interés por la masonería comenzara mucho antes, como resultado de su relación con Miguel Villalba Hervás, antes de su salida de las Islas, o con el militar catalán y miembro del Gran Oriente Ibérico, Francisco Rispá Perpiñá.

24 «Además, su sede estaba abierta a cualquier iniciativa que presentara expectativas de progreso o mejora para la comunidad. Allí se acogió la primera reunión para la creación de la "Sociedad de Socorros Mutuos y Enseñanza Gratuita"; se creó la sociedad mercantil "El Pensamiento"; se reunió un grupo de hombres de empresa que pusieron las bases de la que sería la "Sociedad de Edificaciones y Reformas Urbanas"; y allí se creó el primer círculo mercantil de Tenerife: "La Unión Mercantil y Agrícola”.» (Cola Benítez 1998) 
el Gabinete intentó mutar en 1902 en una institución alternativa: el Ateneo tinerfeño, cuya dirección ostentaría Rafael Calzadilla, pero que echaría el cierre definitivo poco después.

Aunque la pertenencia al Gabinete Instructivo, por su relevancia, ocupa un papel privilegiado en la vida asociativa de Patricio Estévanez, lo cierto es que esta no consiguió monopolizar su actividad filantrópica y cultural. Según Sánchez Morales (2006), también habría sido vicepresidente de la Sociedad La X, asociación, dirigida durante muchos años por Rafael Hardisson, cuyos objetivos parecen estar orientados a la promoción de la ciudad de Santa Cruz. Además, esta vez dentro de una asociación destinada más bien al ocio y al asueto, aparece como secretario del Casino de Santa Cruz, tras la celebración de la junta general del 28 de diciembre de 1889, en la que también resultaron electos: Tadeo Canino, como director, Agustín E. Guimerá, como vicedirector, Gabriel Izquierdo Azcárate, como tesorero, Marcos Peraza, como contador, José Hardisson, como vicecontador y Gonzalo Armendáriz, como bibliotecario (Weyler 1964: 91). Es más, si hacemos caso a una breve descripción hallada en la publicidad de una exposición organizada por la Academia Provincial de Bellas Artes, conservada en el Fondo Estévanez (CEDOCAM_FE_285), Patricio Estévanez también habría sido académico correspondiente de la Real Academia de Historia, presidente de la Sociedad Instructiva de La Laguna, y socio de mérito del Ateneo de La Laguna. En este mismo documento se refieren a Patricio Estévanez como académico y primer consiliario, en la sección de escultura (1913), de la Academia Provincial de Bellas Artes, de la que llegaría a ser presidente accidental, primero, y definitivo, después, en 1915 (RACBA s.f.). Esta nominación da buena cuenta del enorme interés que despertaban en él las artes, tal y como dejaba ver su iniciativa como fundador y editor de la revista Artes y Letras (1903-1904), o el propio salón principal de la casona de Gracia:

Allí hay lienzos de todos los pintores isleños, de Valentín Sanz, González Méndez, Verdugo, don Eduardo Rodríguez, Ángel Romero, Diego Crosa, Juan Botas, y en una palabra, de cuantos pintores, viejos y nuevos, maestros y medianías, se conocen en esta tierra; todos ellos con una expresiva dedicatoria para don Patricio. (Roger 30/03/1909: 1)

Patricio Estévanez, en su apuesta personal a favor de la defensa de Santa Cruz de Tenerife como capital indiscutible de Canarias, ciudad de la que, además, fue cronista oficial, tiene el convencimiento de que esta debe gozar de unas fiestas locales de renombre. Por lo que simboliza, al exaltar los valores del santacrucero, que hicieron valedora del título de ciudad a Santa Cruz de Tenerife, uno de estos festejos tendrá que ser, sin duda, la celebración de la Gesta del 25 de julio o, como se suelen referir a ella en esta época, la Victoria contra Nelson. La otra gran celebración alentada y defendida por Patricio es la que conmemora la fundación de la ciudad, las conocidas como Fiestas de la Cruz o Fiestas de Mayo, reputadas por sus juegos florales. Si bien estas fiestas gozaban desde antiguo de cierto prestigio (Martínez Viera 1967: 42 y ss.), no será hasta la edición de 1892 cuando, impulsadas por Patricio Estévanez, Felipe Verdugo Barlett y el alcalde a 
la sazón, Anselmo Miranda y Vázquez, las fiestas cuenten con la celebración de actos oficiales (Martínez Viera 1967: 45). Además, en su labor como presidente de la Sociedad de Festejos, favorecerá «con todo aquello que redundara a la mayor brillantez del baile dado por la Asociación Obrera ${ }^{25}$ en la noche del $1^{\circ} \mathrm{de}$ Mayo» (CEDOCAM_FE_257), que tuvo lugar en 1902.

Movido por los ideales de la época, promovió acciones de interés público, íntimamente ligadas al bienestar de los ciudadanos de esa gran capital con la que soñaba. En el ámbito urbanístico, además de participar activamente en los proyectos de higienización y de arbolado de los espacios públicos (cfr. a este respecto el artículo de Naranjo Santana en este monográfico), también propugnó ante la Sociedad Económica de Amigos del País de Santa Cruz de Tenerife la creación de la futura calle 25 de julio y del parque García Sanabria, y fue el primero en proponer la construcción de un paseo marítimo hacia el Sur partiendo del Castillo de San Cristóbal, cuya demolición también exigía. En el terreno educativo, además de su constante lucha por la implantación de la biblioteca municipal, es uno de los promotores de la instalación y desarrollo del Establecimiento de Enseñanza Secundaria, al que nos hemos referido anteriormente. Por último, cabe señalar su papel como instigador de la creación del Hospital Pediátrico de Santa Cruz, cuya dirección ostentará el Dr. Costa Guigou, y del que solo disponían en la época las ciudades de Madrid y Barcelona, lo que da buena cuenta de la grandeza que quería otorgar a Santa Cruz. Será también su abnegación por esta ciudad lo que lo llevará incluso a formar parte del equipo de ediles del ayuntamiento capitalino, puesto que abandonaría, posteriormente, para asumir las responsabilidades de vicepresidente del primer Cabildo Insular de Tenerife (1912).

\section{Patricio Estévanez: periodista de profesión y vocación}

Si hay una vertiente de la vida pública en la que Patricio Estévanez se mostró especialmente activo fue en su vocación periodística. Nada más regresar a Tenerife, asume, junto con Adolfo Cabrera Pinto, la dirección del bisemanario de política y literatura El Popular, en el que participaban como redactores los hermanos Zerolo Herrera. Entre 1881 y 1882, también estuvo al frente de la revista homónima de la logia masónica Tinerfe, $\mathrm{n}^{\circ} 114$. En 1882, funda la Ilustración de Canarias, que pretende, en cierta medida, constituir una continuación de la Revista de Canarias, tras la marcha de Elías Zerolo a París, y cuyas páginas, además de abogar por la formación cultural e intelectual de sus lectores, darían voz a varios de los conflictos sociales protagonizados por los trabajadores tinerfeños. De hecho, en 1884, año en el que dejaría de publicarse esta revista, Patricio Estévanez es nombrado, junto con su amigo Gabriel Izquierdo Azcárate, «representante de la prensa tinerfeña en la comisión provincial encargada de proponer las reformas necesarias para la mejora de las condiciones de vida de los trabajadores tinerfeños» (Sánchez Morales 2006: 27).

25 Presidida a su vez por su amigo Antonio Llombet. 
Sin embargo, será con el Diario de Tenerife, fundado en 1886, con el que Patricio Estévanez logrará coronarse en el olimpo del periodismo insular y nacional ${ }^{26}$, como demuestra el hecho de haber sido designado, en 1902, presidente de la Asociación de Periodistas. A pesar de que los ideales políticos de su director, republicanismo federal, eran de sobra conocidos, Patricio Estévanez se esfuerza, desde un principio, en defender una neutralidad política que caracterizaría la línea editorial de esta publicación a lo largo de su existencia. Así se lo hace saber a su íntimo amigo Luis Maffiotte al solicitarle una colaboración so forma de «Crónicas madrileñas»:

Puedes en ellas tratar todo y de todos, hasta de política, siempre que no sea cosa muy palpitante y por ningún caso posibilista ni castelarista. En alusiones o apreciaciones a cosas de partido, cuando quieras atacar a los monárquicos hazlo con condón y cuando hayas de censurar a los republicanos cállate la boca [...]. (Guimerá Peraza 1976: 24)

Un repaso a la nómina de los múltiples colaboradores del Diario viene a refrendar esta intención, pues las plumas que en él rubricaron artículos o crónicas pertenecían a todo el espectro político: Mario Arozena, Andrés Antequera, Manuel Cámara, Leocadio Machado, Amado Zurita, Rosendo García Ramos, Leandro Serra y Fernández de Moratín, Irineo González, Adolfo Cabrera Pinto, Antonio Zerolo, Antonio María Manrique, Luis Maffiotte y La Roche o Manuel Verdugo ${ }^{27}$. De hecho, la línea editorial neutral del Diario era congruente con la práctica social y privada ${ }^{28}$ del propio Patricio, que creía en el debate como herramienta para alcanzar el progreso y que anteponía la tolerancia a sus propias convicciones.

26 La importancia de Patricio como director del Diario no se restringe a las fronteras insulares, sino que su fama llega también a tierras peninsulares, de ahí que, en 1901 la Asociación de Escritores y Artistas, la Prensa y las Sociedades literarias y artísticas de Madrid, se pongan en contacto con él para que se adhiera a la iniciativa del traslado de los restos mortales de Espronceda, Larra y Rosales. (CEDOCAM_FE_331)

27 A modo de ejemplo, indicamos a continuación los autores que contribuyeron en la elaboración del número especial que el 25 de julio de 1897 publicó el Diario de Tenerife para conmemorar el Centenario de la Victoria sobre Nelson: la infanta Paz de Borbón, Práxedes Mateo Sagasta, Eduardo Bento, José Echegaray, el general Azcárraga, el almirante Beránger, Ignacio Pérez Galdós, Antonio Castañón Faes, Ginés de Paredes, Juan Febles Campos, Juan Fernández del Castillo, Fernández Caro y Labra, el marqués de Ahumada, Luis Vidart, Villalón y Concas, Imeldo Serís, Nicolás Estévanez, Gabriel Izquierdo y Azcárate, Manuel Cámara, Darío Cullen, Puerta Canseco, Pulido, Tabares Barlett, Elías, Tomás y Antonio Zerolo, Villalba Hervás, Juan Ravina y Castro, Luis Maffiotte, Santiago Beyro, Amado Zurita, Bernardo Benítez de Lugo y Juan Arzadum.

28 «[Además de Gabriel Izquierdo Azcárate, otros] amigos predilectos lo fueron don José Manuel Pulido, don Rafael Calzadilla, don José Rodríguez Moure, don Juan Febles, don Manuel de Cámara, don Adolfo Cabrera Pinto, don Juan M. Ballester, don Agustín Rodríguez Pérez, don Manuel Quintero, don Mateo Alonso del Castillo, don Rafael Hardisson y don Juan Martí y Dehesa.» (Martínez Viera 1967: 199). 
En principio, también mantendrá cierta imparcialidad en todo lo referido al pleito insular -división provincial o aspiraciones de Las Palmas de Gran Canaria a ostentar la capitalidad. Sin embargo, años después, el Diario evoluciona y se posiciona claramente a favor de Tenerife y de Santa $\mathrm{Cruz}^{29}$, lo que no sentó bien a todos los antiguos colaboradores, entre ellos Luis Maffiotte, al que Patricio responde:

Cómo se conoce que respiras sólo la atmósfera canaria a que te has entregado por completo, según de viejo se dice y repiten malas lenguas. ¿Con que el triste espectáculo que estamos dando es motivo para que se piense mal de esta pobre tierra, sobre todo de Santa Cruz? ¿Quiénes son esos hombres serios? ¿D. Fernando [León y Castillo] y tres paisanos y amigos? ¡Hombre, qué te parece! (Guimerá Peraza 1976: 34)

Además, el Diario de Tenerife va a dar una gran cobertura a los acontecimientos políticos ocurridos allende las fronteras españolas, pues, en principio, no eran susceptibles de ser censurados por los mecanismos de la Restauración. Para ello, Patricio Estévanez desarrolló una extensa red de corresponsalías que le enviaban la información de las principales capitales europeas. La necesidad de acelerar la transmisión de la información, supeditada a la lentitud de los circuitos informacionales tradicionales, es una de las razones que llevó a Patricio a erigirse, junto con el diputado Feliciano Pérez Zamora, en uno de los principales promotores del proyecto de conexión por cable telegráfico entre la Península y Canarias (1883), lo que le valió el título de Telegrafista de Honor (Sánchez Morales 2006: 29).

De entre todas las redes informacionales internacionales en las que participaba Patricio Estévanez, sin duda, la más importante era la que lo conectaba con el París de su juventud y, sobre todo, con su hermano. Si bien en la correspondencia consultada, siempre se observa alguna palabra cariñosa o amistosa -sobre todo cuando Nicolás rememora sus andanzas de juventud, habla de temas íntimos, o habla de las constantes visitas de sus amigos isleños a París ${ }^{30}-$, lo cierto es

29 Movido por su patriotismo, cada vez que tiene oportunidad, Patricio hace un alegato a favor de Santa Cruz de Tenerife. Valga como anécdota la manera en la que, en una carta fechada el 13 de julio de 1893, justifica el retraso de su respuesta para formar parte de la Junta Provincial de promoción de la Exposición Universal que ha de celebrarse en Madrid en 1894: «gracias por la distinción con que me favorece, significándole de paso que el retraso con que lo hago -así como el no haber recibido los impresos que me anuncia- se debe a que la referida comunicación ha llegado a mis manos también con mucho retraso, porque -como desgraciadamente sucede con harta frecuencia en los centros oficiales de la Península- venía el sobre dirigido a Las Palmas y no a esta Capital; confusión que, por lo mismo que se repite mucho, no hace gran honor a los conocimientos geográficos, o a la buena fe de los empleados subalternos, que ignoran, o parecen ignorar, que no es aquel pueblo sino Santa Cruz de Tenerife, la Capital de la provincia de Canarias.» (CEDOCAM_FE_294).

30 En varias ocasiones Nicolás cuenta a Patricio de primera mano las andanzas de algunos amigos isleños de paso por la capital francesa (Villalba, Rallo, Quintero, Delgado, Ballester, Rodríguez Núñez, los Guimerá, Rafael Hardisson, Azcárate...), 
que, con el paso del tiempo, este intercambio va adquiriendo un carácter más informacional, político o comercial en detrimento de la naturaleza afectiva que cabría esperar. Las gestiones editoriales para eventuales publicaciones de la obra de Nicolás en Canarias, las ofertas de anunciantes en el Diario ${ }^{31}$ o el interés por la rentabilidad de posibles negocios en las Islas ${ }^{32}$ conviven en el intercambio epistolar con información política proveniente de fuentes directas, desconocida en muchos casos por los periódicos nacionales, o con información íntima. La dificultad, en muchos casos, estriba en que es casi imposible distinguir al Patricio, hermano y amigo, del Patricio, director del Diario de Tenerife, como demuestra el tratamiento que, aunque sea de manera jocosa y anecdótica, le reservan algunos de sus más íntimos $\operatorname{amigos}^{33}$ en una misiva enviada desde París en 1889: «Director [del] Diario [de] Tenerife | Saludámosle, brindando prosperidad [al] Archipiélago»(CEDOCAM_FE_197). Por ello, en muchos casos, no se sabe a ciencia cierta si la información que recibe de sus contactos en la capital francesa tiene una finalidad informativa personal o si, en cambio, se pretende que Patricio dé difusión pública a la información transmitida. Este es el caso de ciertos recortes de periódico enviados por el pintor Manuel González Méndez a Patricio (CEDOCAM_FE_324) en los que se da cuenta de su recibimiento y de los premios obtenidos en una exposición en París. Como bien sabemos, Patricio guarda con celo cada uno de los documentos informativos que llegan a sus manos ${ }^{34}$, pero también puede publicarlos, de modo que su amigo se

principalmente por asuntos de negocio o para visitar las Exposiciones albergadas en París: «Rallo no ha perdido el viaje, pues si bien se ha ido sin comprar ni atender a sus negocios, en cambio ha sido aclamado por la muchedumbre; sus arengas acababan con estas palabras: ¡Vive la République Française! ¡Vive Teneriffe!» (CEDOCAM_ FE_217).

31 «Los de las píldoras te escribirán; se han quedado con las ganas de saber exactamente cuál es la tirada, pues yo les he dicho que no sé más que una cosa: que es el de mayor tirada en la provincia, por lo que presumo que tirará a lo menos de 4 a 9 mil. Creo que aceptan los precios, pero puede ser que te pidan la exclusiva (en píldoras). No lo aceptes, pues hay otros artículos similares que se anuncian precisamente donde lo hacen las Pink. Al contrario, cuando las anuncies debes mandar un número a todos los que les hacen competencia, que puedes verlo en la prensa de cualquier parte y especialmente en la de aquí. Yo no tengo ningún interés en esto, sino el deseo de que pueda serte útil.» (CEDOCAM_FE_931).

32 «Mi amigo Lapuya me da el encargo de preguntar qué puede hacerse ahí en cuestión de tranvías y de aguas, pues para estas cosas le han hecho proposiciones de dinero». (CEDOCAM_FE_888)

33 La carta, fechada el 11 de octubre de 1889, viene firmada por Nicolás Estévanez, Manuel González Méndez, Elías Zerolo, el Dr. Real, Arozena, Llarena, Azcárate y R. Hardisson (CEDOCAM_FE_197). Suponemos que se hallaban en la capital francesa con motivo de la Exposición Universal de 1889, presidida por la Torre Eiffel, celebrada entre el 6 de mayo y el 31 de octubre.

34 «[... Nadie ha escapado a la manía coleccionista de D. Patricio. Del rey abajo puede decirse que todos han caído en las cárceles de sus cajones de antiguallas, para sepultarse para siempre en incómoda tumba de papeles, expuestos a que la polilla les devore con saña impía.» (Roger 30/03/1909: 1). 
transfiguraría en un corresponsal, y, por lo tanto, el tipo de relación social no sería exactamente el mismo. Al contrario, también encontramos testimonios en los que Patricio solicita a algunos de sus amigos que le faciliten datos, sin que se pueda elucidar si lo hace a título personal o como director: «Me ha dicho Zerolo que le has pedido unos datos sobre los franceses del 97» (CEDOCAM_FE_728). En otros casos, esta dicotomía personal $v s$. profesional no es ni siquiera operante. Así, en varias ocasiones, Elías Zerolo o su hijo, Miguel, apelan a su amigo Patricio en calidad de director del Diario, para que los nombre corresponsales oficiales en París y, de esta manera, poder asistir gratuitamente a ciertos acontecimientos, como las Exposiciones Universales.

Se dice que esta vez no tendrá toda la prensa entrada gratis a la Exposición, y no quiero ser de los últimos corresponsales (es un decir) que la soliciten. Necesito, pues, un nombramiento de corresponsal en debida forma, en papel con el membrete del "Diario", etc., y legalizado en ese Consulado de Francia. (CEDOCAM_FE_2411)

En el sentido inverso, en repetidas ocasiones, Nicolás otorga el poder de votar por procuración a su hermano Patricio, que, además, comparte ideales políticos. También se le encomienda la recepción de varios viajeros y personajes relevantes de paso por la Isla, que llevan la recomendación de sus amigos isleños de París. Es el caso, por ejemplo, del Sr. Edmond Cotteau, en 1888, que goza tanto del favor de Elías Zerolo como del Dr. Verneau:

Querido Patricio: te recomiendo eficazmente a Mr. Edmond Cotteau, viajero y escritor francés, que se propone visitar nuestras queridas islas. Mr. Cotteau ha publicado ya 3 volúmenes de viajes en la colección de Hachette. El Dr. Vernau [sic] lo recomienda a sus amigos de esa. Como ha de escribir su viaje, deseo que vea lo bueno que tiene Tenerife. (CEDOCAM_FE_2413)

La predisposición de Patricio Estévanez para ayudar, no solo a sus contactos en Francia, sino a todo aquel que solicitaba su ayuda o colaboración, sobre todo si el fin perseguido era de índole filantrópica, lo precedía. Son numerosas las peticiones conservadas en el Fondo Estévanez que atestiguan dicha predisposición, como la que, desde La Orotava, le envía Antonio M. Casañas:

Como V. está siempre dispuesto a intervenir en todo lo bueno, le suplico en mi nombre y en el de los demás que suscriben ese Reglamento, tenga a bondad de presentarlo a nuestro nombre, al Sr. Gobernador, y recoger uno de los dos ejemplares con la firma de dicha autoridad y sello del Gobierno a fin de que comience a correr el plazo para poder constituirse la Sociedad de que se trata. (CEDOCAM_FE_873)

La extensión e importancia de las redes urdidas por Patricio Estévanez a lo largo de su existencia lo llevan a erigirse, muchas veces, en intercesor en el desarrollo, y buen desemboque, de procesos, negocios o nombramientos de diversa índole. En numerosas ocasiones, este, en nombre de diferentes grupos o asociaciones, o como respaldo de las mismas, actúa como intermediario a la hora de contactar con cierta persona o entidad. Su participación como enlace, hace que la relación social que, en un principio, debía establecerse entre una 
sociedad dada y la persona en cuestión pierda su naturaleza aséptica y se recubra de cercanía, de manera que la petición se traslada al ámbito íntimo y personal. Dicho de otro modo, el apelar a la figura de Patricio Estévanez como mediador transforma una petición de colaboración en un favor personal (y personalizado). Así, por ejemplo, observamos cómo la intercesión de Patricio Estévanez refuerza la petición que la Sociedad Económica hace al pintor tinerfeño, afincado en Cataluña, Nicolás Alfaro y Brieva, para que participe en la exposición que organiza dicha entidad en 1894:

[...] he recibido la invitación de V. a 2 pie de la Sociedad Económica, para que concurra a la exposición de este año. Mucho tiempo hace que ando dejado de toda clase de palenques, pero el deseo de dejar complacido a V. y a mis sobrinos me hace quebrantar mis propósitos. (CEDOCAM_FE_96)

En este sentido, son muchos los amigos que le escriben para que medie en su favor. Este es el caso, por ejemplo, de Diego Guigou y Costa, médico director del Hospital de niños de Santa Cruz de Tenerife, quien, en una misiva enviada a Madrid con motivo de la estancia que Patricio realiza para su tratamiento ocular con radio (1917), le pide que intervenga para que la concesión de la gran Cruz no quede en saco roto:

[...] le agradecería muchísimo que V. que puede seguir ahí los pasos de este expediente, procure que no se estanque, y que sean eficaces las gestiones hechas con el anterior Ministro [Sánchez Guerra]; y en todo caso ponerme al corriente de lo que ocurra y de lo que pudiera hacerse. (CEDOCAM_FE_72)

Como director del Diario, Patricio constituía ciertamente un poder factual y de opinión fundamental, lo que además de otorgarle un peso considerable a la hora de ponderar ciertas decisiones, como acabamos de ver, le aseguraba un lugar central en la celebración de todos los acontecimientos que gozasen de cierta relevancia social. Su desempeño en el cargo de director del periódico decano de Santa Cruz de Tenerife nunca causó mella en su incólume naturaleza: la de periodista, lo que lo llevó, en muchas ocasiones, a realizar crónicas, rara vez firmadas, de acontecimientos relacionados con la sublimación de la cultura y la ciencia, así como otros que no aspiraban sino al entretenimiento, como las veladas, conciertos o bailes de disfraz organizados por la Sociedad Filarmónica Santa Cecilia ${ }^{35}$ o del Círculo de Amistad-XII de Enero en sus salones o los concursos de bandas de música o de colombofilia, organizados respectivamente por el Club Tinerfeño y por la Real Sociedad Colombófila de Tenerife, con don Juan Marín y de Foronda al frente, en los salones de la Sociedad Frégoli (CEDOCAM_FE_2160).

35 A modo de ejemplo, indicamos que, en la velada organizada en julio de 1897, probablemente, con motivo del Centenario de la Gesta contra Nelson, hubo un concierto a cargo de la Sociedad Filarmónica Santa Cecilia, se ofreció una comida para pobres, amenizada por la banda de aficionados La Bienhechora, y se realizó un asalto a las armas por la Academia de esgrima, seguida de una reunión de confianza (CEDOCAM_FE_679). 
A pesar de que, sobre el papel, Patricio Estévanez seguirá figurando como director de la publicación hasta su último número, su menguada salud hace que, en 1917, la dirección de facto del Diario pase a manos de Ramón Gil-Roldán, Andrés Orozco, Rubens Marichal y Francisco Martínez Viera (Martínez Viera 1967: 202). El cese de la actividad del periódico supondrá para Patricio Estévanez una primera muerte, la que pondría fin, de alguna manera, a su vida pública y profesional; la segunda, tal vez menos significativa para él, le llegaría casi una década más tarde, en 1926.

\section{Conclusiones}

El repaso biográfico de Patricio Estévanez ha permitido dibujar las múltiples redes sociales en las que se organizaban las relaciones íntimas, laborales, ideológicas y políticas de este destacado personaje de la sociedad santacrucera finisecular. Lejos de constituir cadenas asintóticas de nodos, se descubre como huella de su sociabilidad un entramado en el que se entremezclan los nombres -pertenecientes mayoritariamente a las élites culturales, económicas y políticas-, se imbrican los objetivos e, incluso, se superponen las acciones realizadas por estos al amparo de las diferentes asociaciones que surgen tras la revolución Gloriosa. Se ha podido observar además que, al extrapolar esta realidad egocentrada a una escala urbana, delimitada por un espacio -Santa Cruz de Tenerife- y por una época - la marcada por la etapa vital de nuestro biografiado-, existe un elevado grado de identificación en lo que a redes sociales se refiere. Un tejido que, si bien no esconde los distintos colores que representan la variedad de opiniones e ideas, muchas veces frontalmente opuestas, presenta una urdimbre homogeneizada por la tolerancia y por la búsqueda constante del progreso. Una urdimbre, cuya impronta indeleble ha quedado plasmada, con el paso del tiempo, en un entramado urbano en el que los nombres de las calles, plazas y avenidas recuerdan a aquellos próceres que marcarían para siempre la historia de Santa Cruz de Tenerife.

\section{Bibliografía}

Agulhon M., 2016, Política, imágenes, sociabilidades: de 1789 a 1989, Zaragoza, Prensas de la Universidad de Zaragoza.

Bonafoux y Quintero L., 1907, Bombos y palos, Paris, Ollendorff.

Cola Benítez L., 1998, «El debate de las ideas al servicio del progreso y la cultura. El

Gabinete Instructivo de Santa Cruz de Tenerife (1869-1901)», transcripción de la conferencia pronunciada en el Instituto Cabrera Pinto, $<$ http://amigos25julio. com/index.php?option $=$ com_content\&view $=$ article $\&$ id $=660$ :el-debate de-ideas-al-servicio-del-progreso-y-la-cultura-el-gabinete-instructivo-desanta-cruz-de-tenerife-1869-1901\&catid=65: conferencias \&Itemid=105>, consultado el 30/10/2020. 
Cola Benítez L., 2001, El Gabinete Instructivo de Santa Cruz de Tenerife (18691901), Santa Cruz de Tenerife, Organismo Autónomo de Cultura del Excmo. Ayuntamiento de Santa Cruz de Tenerife.

De Paz Sánchez M. y Alfonso Da Costa C. (eds.), 2008, Papeles masónicos inéditos (Tenerife, siglo XIX), Santa Cruz de Tenerife, Ediciones Idea.

Estévanez Murphy N., 1903, Rastros de la vida. Artículos y remembranza, Paris, Garnier Frères.

Estévanez Murphy P., 08/05/1879, «Correspondencia de París», Revista de Canarias, p. 171-173.

Estévanez Murphy P., 21/05/1879, "Correspondencia de París», Unión Lagunera, p. 2.

Estévanez Murphy P., 01/01/1917, «Uno que se rinde», Diario de Tenerife: periódico de intereses generales, noticias y anuncios, p. 1.

Fischer Hubert D., 1994, El libro español en París a comienzos del siglo XX. Escritores y traductores, tesis de doctorado, Universidad Rovira i Virgili.

Gil-Roldán R., 01/01/1917, «A renglón seguido», Diario de Tenerife: periódico de intereses generales, noticias y anuncios, p. 1.

González Pérez P.B., 1999, «Escuela Libre de Derecho», Boletín Millares Carlo, n. ${ }^{\circ}$ 18 , p. 229-246.

Guimerá Peraza M., 1974, «Patricio Estévanez, periodista y ciudadano», El Museo Canario, n. ${ }^{\circ} 35$, p. 89-122.

Guimerá Peraza M., 1975, Cartas de Nicolás Estévanez, Tenerife, Aula de Cultura de Tenerife.

Guimerá Peraza M., 1976, Patricio Estévanez. Cartas a Luis Maffiotte, Tenerife, Aula de Cultura de Tenerife.

Imízcoz Beunza J.M. y Arroyo Ruiz L., 2011, «Redes sociales y correspondencia epistolar. Del análisis cualitativo de las relaciones personales a la reconstrucción de redes egocentradas», REDES-Revista Hispana para el análisis de redes sociales, vol. 21, n. $^{\circ} 2$, p. $98-138$.

López Lapuya I., (s.f.), La Bohemia española en París a finales del siglo pasado: desfile anecdótico de políticos, escritores, artistas, prospectores de negocios, buscavidas y desventurados, Paris, Casa Editorial Franco-Ibero-Americana.

Martínez Viera F., 1967, El antiguo Santa Cruz: Crónicas de la capital de Canarias, La Laguna, Instituto de Estudios Canarios.

Pérez Roldán C., 1999, «La prensa republicana madrileña durante el siglo XIX: "La Igualdad" y "El Combate" como ejemplos de periódicos republicanos», Historia y comunicación social, n. ${ }^{\circ} 4$, p. 317-340.

[RACBA] Real Academia Canaria de Bellas Artes (s.f.), Académicos, <https:// racba.es/listado/estevanez-y-murphy-patricio/>, consultado el 30/10/2020.

[RSEAPT] Real Sociedad Económica de Amigos del País de Tenerife, (s.f.), Histórico de directores, <www.rseapt.es/es/historico-de-directores>, consultado el 30/10/2020. 
Reyes González N., 2016, Desde la sombra del almendro. Nicolás Estévanez y Murphy (1838-1914), Madrid, Mercurio Editorial, vol. 1.

Rodríguez L., 2001 [1940], Los árboles históricos y tradicionales de Canarias, vol. 1, Santa Cruz de Tenerife, Editora de Temas Canarios.

Rodríguez Escudero J.G., 2009, «Manuel González Méndez. Centenario de la muerte del más grande de los pintores canarios del XIX», Revista Bienmesabe, n. ${ }^{\circ}$ 293, <https://www.bienmesabe.org/noticia/2009/Diciembre/manuelgonzalez-mendez-centenario-de-la-muerte-del-mas-grande-de-los-pintorescanarios-del-xix>, consultado el 13/08/2020.

Roger L., 30/03/1909, «Santa María de Gracia. La familia de los Estévanez», El Progreso, n. ${ }^{\circ} 1070$, p. 1-2.

Sánchez Morales J., 2006, Patricio Estévanez, Santa Cruz de Tenerife, Ediciones Ideas, Colección «Periodistas de Canarias».

Weyler y López de Puga V., 1964, La pequeña historia de un gran casino: el Casino e Santa Cruz de Tenerife, Tenerife, Isis.

Yanes Mesa J.A., 2003, Historia del periodismo tinerfeño 1758-1936: una visión periférica del periodismo español, Tenerife, Centro de la Cultura Popular Canaria.

Zerolo E., 03/02/1880, «Conversación quincenal», Revista de Canarias, n. o 29, p. 47. 